\title{
Acute Sub temporal and Infratemporal Dumbbell Abscess Secondary to Tooth Extraction: Case Report
}

\author{
Yam Bahadur Roka ${ }^{1}$ \\ ${ }^{1}$ Department of Neurosurgery, Neuro Cardio and Multispecialty Hospital, Biratnagar, Nepal \\ Correspondence: \\ Dr. Yam B Roka M.S, M.Ch (Neurosurgery), FNNI (Skull Base Surgery), IFAANS \\ Chief of Neurosurgery and Medical Director \\ Neuro Cardio and Multispecialty Hospital \\ Jahada Road, Biratnagar-13, Nepal \\ Email: dryamroka@yahoo.com \\ Phone: +9779841256560
}

\begin{abstract}
To present a case of acute temporal and infratemporal dumbbell abscess following tooth extraction and discuss the possible anatomic pathways of spread of odontogenic infections. This is a case of right maxillary tooth extraction following which he developed local infection that spread to the temporal and sub temporal space. The history and examination revealed the infection spreading to the buccal and sub temporal space with trismus and feeding problems. Intraoral and external drainage along with antibiotics led to the resolution of the abscess. Of the many complications of tooth extraction infection spreading along the temporalis with formation of a dumbbell abscess can lead to severe discomfort and septicemia if not detected and treated early. A case with successful management and result are discussed.
\end{abstract}

Key Words: Abscess, Dental Caries, Maxillofacial, Odontogenic Infection, Sub temporal Abscess

$\mathrm{S}$ imple tooth extraction can have disastrous complication as illustrated by this case report. It often leads to considerable pain, trismus and feeding difficulties. Knowledge of the anatomy and the pathways of spread can help in early diagnosis and management of this uncommon complication. There are various routes of spread of the infection from the maxilla depending on the primary site whether anterior or posterior of the dental infection. Infection spread can be rapid once the temporal fascia is involved extending superiorly to its attachment on the skull. Early recognition and investigation with computed tomography (CT) can help in diagnosis and treatment of this complication. There are very few reports of tooth infection spreading to the sub temporal space in the literature and this report aims to present one such case. The case report presented is of a 75-year-old man who was referred for progressively enlarging right side cheek and head along with fever and trismus following extraction of the upper second molar. Brief review of the methods of spread along with present management options of these infections is discussed.

\section{Case Description:}

A 75-year-old male underwent extraction of his right tooth in a private dental clinic following which he developed progressively enlarging swelling of the right cheek. He also had fever and was started on antibiotics. On the third day of the dental procedure the swelling had increased to involve the whole of the right side and extended superiorly to the right side of the head (Figure 1). The dental surgeon on suspicion of abscess had incised and drained pus from the cheek before referring the patient to this hospital. On examination he had high grade fever with associated severe trismus with difficulty in opening the mouth and swallowing. The local temperature was elevated and the whole of the right cheek and the sub temporal space was swollen with edema and induration spreading to the attachment of the 
temporalis fascia. The impression by the zygomatic arch gave the shape of a dumbbell abscess.

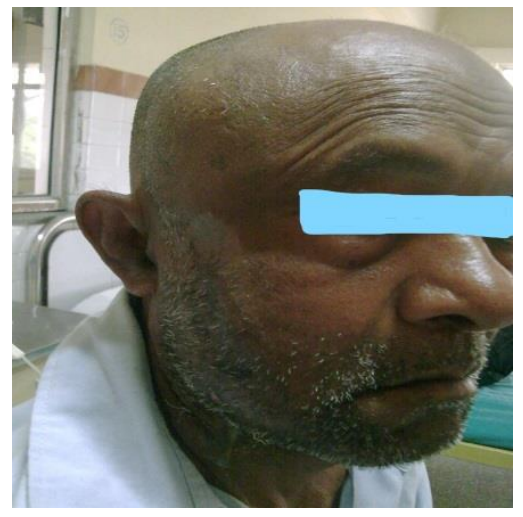

Figure 1: Clinical photo showing the swollen right sided cheek, face and temporal fossa. Note the external incision on the lower edge of the swelling.

Urgent blood picture showed leucocytosis with granulocytosis and contrast CT scan revealed a large abscess in the mandibular space involving the coronoid process and spreading contiguously along the temporal muscle to extend superiorly into the sub temporal space (Figure 2A and 2B).
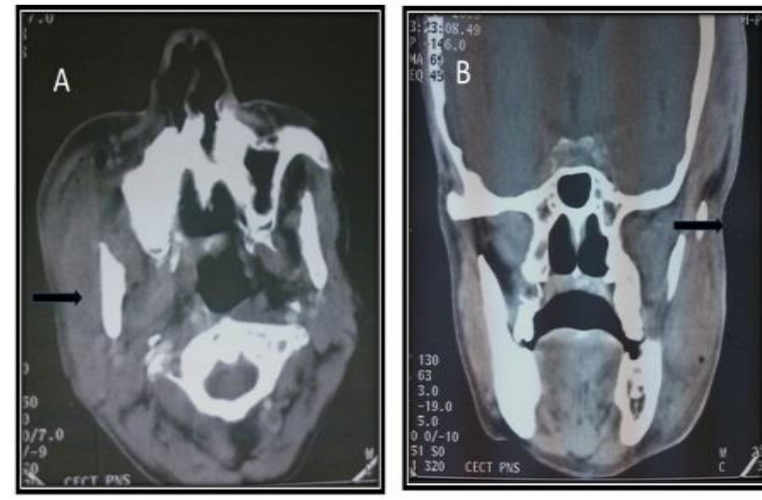

Figure 2: (A) Axial contrast CT scan showing the abscess involving the mandible and the masticator space. (B) Coronal CT scan showing the masticator abscess in contiguous spread to the sub temporal space. Abscess shown as black arrows.

The jaw, maxilla and the temporal bones were normal. There was active pus discharge from the previous cheek incision and needle aspiration of the temporal muscle drew thick pus mixed with blood. He underwent emergency intraoral and temporal incision with drainage of the pus with central venous line insertion. The Gram stain showed gram negative organism. He was kept on intravenous antibiotics based on the sensitivity of the pus culture which grew Citrobacter spp. The abscess slowly reduced in size and he was able to feed orally on the third day of antibiotics. One more repeated drainage was done and there was complete resolution of the abscess on the ninth day. The temporal abscess resolved without any further drainage. He was discharged on the tenth day with a week of antibiotics.

\section{Discussion}

The anatomy of the maxillofacial compartment is complex and divided into many compartments by the masticator muscles and fascia. ${ }^{1}$ Infection from odontogenic origin is common in the maxillofacial area and its spread depends on the origin of the infection itself. ${ }^{2}$ It can involve the nasal or orbital space if anterior and the maxillary sinus if posterior in origin. ${ }^{3-5}$ The spread of infection can be rapid once it involves the temporalis muscle aiding to its spread beyond the maxillofacial compartment., Fine cut images by computerized tomography (CT), or magnetic resonance imaging has been proven to help in the diagnosis and management of these infections. ${ }^{8,9}$ The presence of teeth also leads to spread of infection to the jaws by direct spread and is the commonest cause of osteomyelitis of the latter. ${ }^{10}$

The treatment of localized infection can be antibiotics alone but presence of abscess needs drainage externally or intraorally which is preferred. ${ }^{11}$ Detailed study of the pathways of the spread of odontogenic infections are given by Obayashi et al. These authors reconfirmed the earlier observation that although fascial attachments determine the spread and limitation of these infections the muscle attachments also play an important role in their spread. ${ }^{12,13}$ Some of the other complication reported in literature after tooth extractions are cranial osteomyelitis, temporal fistula, abscess in an immunocompromised patient and orbital visual loss. ${ }^{14-17}$

\section{Conclusion:}

Dental procedures are common. Most of the complications are secondary to infection and are minor that usually resolve with antibiotics. This case presents an uncommon complication with acute spread to areas beyond the maxillary space. 
Knowledge of the anatomy and the pathways of spread can help in early diagnosis and management of the uncommon but possibly life-threatening complications. Thus, it is pertinent to check for extension of infection in all cases of post tooth extraction cellulitis with early drainage of the deep abscess to prevent further morbidity.

\section{References:}

1. Goldberg MH, Topazian RG. Odontogenic infections and deep fascial space infections of dental origin. In: TopazianRG, Goldberg MH, Hupp JR, editors. Oral and maxillofacial infections. 4th ed. Philadelphia: Saunders 2002.p. 158-87. [Citation] [ Article]

2. Birn H. Spread of dental infections. Dent Pract Dent Rec 1972; 22:347-56. [Pubmed]

3. Yoshiura K, Ban S, Hijiya T, et al. Analysis of maxillary sinusitis using computed tomography. Dentomaxillofac Radiol 1993; 22: 86-92. [Pubmed]

4. Kretzschmar DP, Kretzschmar JL. Rhinosinusitis: review from a dental perspective. Oral Surg Oral Med Oral Pathol Oral Radiol Endod 2003; 96:128-35. [Pubmed]

5. Fowler EB, Breault LG, Galvan DA. Nasal fistula associated with dental infection: a report of a case. J Endod 2000; 26:374-6. [Pubmed]

6. Bullock JD, Fleishman JA. The spread of odontogenic infections to the orbit: diagnosis and management. J Oral Maxillofac Surg 1985; 43:749-55. [Pubmed]

7. Obayashi N, Ariji Y, Goto M, et al. Spread of odontogenic infection originating in the maxillary teeth: computerized tomographic assessment. Oral Surg Oral Med Oral Pathol Oral Radiol Endod 1991; 98:223-31. [Pubmed]

8. Ariji E, Moriguchi S, Kuroki $\mathrm{T}$, et al. Computed tomography of maxillofacial infection. Dentomaxillofac Radiol 1991; 20:147-51. [Pubmed]

9. Yonetsu K, Izumi M, Nakamura T. Deep facial infections of odontogenic origin: CT assessment of pathways of space involvement. AJNR Am J Neuroradiol 1998; 19:123-8. [Pubmed]

10. Shafer WG. Diseases of the pulp and periapical tissues. In: Shafer WG, Hine MK, Levy BM, eds. A textbook of oral pathology,4th edn. Philadelphia, PA: Saunders 1993.479525. [Citation]

11. Akst LM, Albani BJ, Strome M. Subacute infratemporal fossa cellulitis with subsequent abscess formation in an immunocompromised patient. Am J Otolaryngol 2005; 26:35-8.

12. Morse DR. Oral pathway of infection, with special reference to endodontics. J Br Endod Soc 1972; 6:13-6. [Pubmed]

13. Spilka CS. Pathways of dental infections. J Oral Surg 1966; 24: 111-24. [Pubmed]

14. Adams JR, Bryant DG. Cranial osteomyelitis: a late complication of a dental infection. Br J Oral Maxillofac Surg 2008; 46:673-4. [Pubmed]

15. Zachariades N, Vairaktaris E, Mezitis M, et al. Orbital abscess: visual loss following extraction of a tooth--case report. Oral Surg Oral Med Oral Pathol Oral Radiol Endod 2005; 100:70-3. [Pubmed]

16. Ertaş Ü, Yalçın E. Chronic temporal abscess resulting from a periapical abscess of the upper right first molar. British Journal of Oral and Maxillofacial Surgery. 2009 Jun 1;47(4):332 [Pubmed]

17. Park MY, Kim HS, Ko HC, Kim MB, Kim BS. Infratemporal fossa abscess of dental origin: a rare, severe and misdiagnosed infection. Journal of the Korean Association of Oral and Maxillofacial Surgeons. 2018 Feb; 44(1):37. [Pubmed] 